\title{
A importância da informação estatística para as políticas sociais no Brasil: breve reflexão sobre a experiência do passado para considerar no presente
}

\author{
Paulo de Martino Jannuzzi ${ }^{\star}$
}

\section{Introdução}

O Brasil seria diferente do que é hoje se não fossem as informações produzidas pelo IBGE e por outras instituições do Sistema Estatístico Nacional. Com todas as iniquidades sociais que ainda persistem no país, o quadro seria seguramente pior caso não houvesse informações estatísticas levantadas há mais de 80 anos ou quase 150 anos, se forem considerados os esforços de realização do primeiro Censo Demográfico em 1872, no final do Império, quase 20 anos depois do planejado, pelas resistências da elite latifundiária e escravocrata da época. Não há como não reconhecer que parte das conquistas republicanas de universalização da educação básica, do acesso à água, redução da pobreza, promoção do desenvolvimento regional, ampliação da cobertura do emprego formal e da previdência pelo vasto território brasileiro deve-se à disponibilidade de informação estatística de boa qualidade e cobertura levantada pelo IBGE e outras instituições como o Instituto Nacional de Estudos e Pesquisas Educacionais, os departamentos de estatísticas e pesquisas dos Ministérios e órgãos subnacionais de planejamento e estatística.

É claro que a efetividade das políticas sociais depende de uma série extensa de fatores, mas a informação estatística cumpre papel instrumental relevante em todas as fases de implementação de um programa público, da formulação à avaliação do mesmo (HOWLETT et al., 2013). Políticas sociais são muito intensivas em informação no processo de seu desenho

\footnotetext{
* Escola Nacional de Ciências Estatísticas (Ence) do Instituto Brasileiro de Geografia e Estatística (IBGE), Rio de Janeiro-RJ, Brasil (paulo.jannuzzi@ibge.gov.br; https://orcid.org/0000-0003-3528-7497).
} 
e implementação. Elas se estruturam como sistemas complexos, articulando programas de natureza universal com ações redistributivas em várias áreas setoriais, operados por agentes em diferentes níveis federativos de governo, em contextos desiguais em termos de capacidade de gestão e de perfil socioeconômico de públicos-alvo. Como discutido em Jannuzzi (2016), para que essas políticas e programas sociais consigam cumprir seus objetivos específicos e contribuir para maior efetividade social da ação pública, é necessário produzir informação e estudos de diferentes naturezas - levantamentos diagnósticos detalhados, sistemas de indicadores de monitoramento de ações, pesquisas de avaliação de processos e de resultados de programas, investigação de potenciais impactos e externalidades negativas -, valendo-se de uma combinação plural de metodologias (quali, quanti e participativas), com abordagem de diferentes sujeitos envolvidos (beneficiários, usuários, técnicos na ponta e gestores).

Entre tais levantamentos figuram, em especial, os Censos Demográficos, a cinquentenária Pesquisa Nacional por Amostra de Domicílios (PNAD, e agora PNAD-Contínua) e as edições, há 20 anos, da Pesquisa de Informações Básicas Municipais (Munic). Essas pesquisas parecem se constituir nos levantamentos estatísticos mais impactantes para formulação e avaliação de políticas sociais no Brasil. Há certamente outras pesquisas importantes a serem mencionadas, como as Estatísticas do Registro Civil, as Pesquisas de Orçamento Familiar, a Pesquisa Mensal de Emprego, a Economia Informal Urbana e, mais recentemente, a Pesquisa Nacional de Saúde, cujas contribuições precisam ser resgatadas em outros textos e estudos.

Os Censos têm permitido o desvelamento dos bolsões de pobreza e outras iniquidades sociais no território nacional, nos municípios e seus bairros. As PNAD (e PNAD-C) possibilitam acompanhar os efeitos - e defeitos - de políticas e programas nas mais variadas áreas setoriais, tais como trabalho, educação, saúde, previdência e assistência social, entre as principais. As Munic e, desde 2012, as Pesquisas de Informações Básicas Estaduais (Estadic) têm viabilizado o dimensionamento da capacidade subnacional de gestão de políticas, de equipamentos públicos e de atendimento de serviços sociais. As três pesquisas se destacam pelo conjunto integrado de informações que proporcionam, pela abrangência temática, regularidade e cobertura territorial. Essas características garantiram a produção de dados cruciais para identificação de demandas sociais, elaboração de diagnósticos, formulação de políticas e programas e avaliação da efetividade dos mesmos ao longo das últimas décadas.

É o que se procura resgatar de forma breve e ensaística nesse texto, como subsídio para o debate acerca do mérito e dificuldades de financiamento do Censo 2020, dos suplementos temáticos das PNAD-C, Munic e outras pesquisas do Sistema Estatístico. Trata-se de um debate que precisa ser realizado com perspectiva histórica e pluralidade de visões acerca do uso da informação estatística para o Estado e sociedade no país. Não são pouco gravosas as consequências da eventual descontinuidade de séries históricas de longa data ou a decisão de adiar a captação de dados acerca de novas questões da agenda social no país. 


\section{Censos Demográficos e o dimensionamento de demandas para políticas públicas}

Estatísticas públicas, em especial indicadores sociais, cumprem papel fundamental no dimensionamento de questões sociais latentes na sociedade que, vocalizadas adequadamente, podem entrar na agenda prioritária de governo. Indicadores, de um lado, instrumentalizam as demandas de grupos organizados em partidos políticos, sindicatos, associações patronais, imprensa e outras instituições e, de outro, oferecem aos técnicos e gestores uma representação estruturada passível de ser avaliada comparativamente com outras demandas concorrentes. A fome, a pobreza, o baixo desempenho escolar, os problemas no acesso a serviços de saúde, a drogadição, a violência e várias outras iniquidades disputam as prioridades em qualquer agenda governamental no país. Quanto mais bem dimensionadas e caracterizadas essas questões por meio de indicadores, mais argumentos são fornecidos aos grupos de pressão e à sociedade na disputa de prioridades na agenda social e na alocação de recursos orçamentários.

Um bom diagnóstico para programas públicos deve contemplar o levantamento de indicadores sobre as características do público-alvo a atender, as condições sociais do contexto em que vivem, as potencialidades e fragilidades da base econômica local e regional (que pode criar condições melhores ou mais desafiadoras para o programa), os condicionantes ambientais (que restringem certas estratégias de desenvolvimento e potencializam outras) e o nível de participação da sociedade (que pode garantir maior controle social dos recursos e dos resultados dos programas). Também devem fazer parte do diagnóstico os indicadores demográficos, em especial aqueles que permitam apresentar as tendências de crescimento populacional passado e as projeções demográficas futuras, já que possibilitam o dimensionamento dos públicos-alvo dos diversos programas no futuro. Demandas sociais dependem do perfil demográfico: população jovem requer esforços de alocação e recursos em educação; população mais idosa necessita de serviços assistenciais e previdenciários, para citar dois exemplos recorrentes na comunidade abepiana.

As estatísticas públicas, especialmente aquelas levantadas nos Censos Demográficos, têm sido fundamentais na formulação de políticas públicas nos três níveis de governo, ao permitirem a elaboração de diagnósticos socioeconômicos com abrangência temática, detalhe territorial e comparabilidade histórica. Indicadores de renda e pobreza, de acesso domiciliar a saneamento básico, energia elétrica e pavimentação, de ocupação, subocupação e desemprego de chefes de família, de evasão e atraso escolar de crianças, de analfabetismo de adultos, de mortalidade de jovens negros, de migração e deslocamentos para escola e local de trabalho são essenciais para o dimensionamento de demandas sociais, proposição de políticas e programas e para orientação do investimento público e privado em infraestrutura urbana e serviços (JANNUZZI, 2017).

Pela comparação com os dados levantados em oportunidades anteriores e entre distintas localidades, os Censos têm permitido avaliar a efetividade - ou não - da ação governamental em várias áreas setoriais. Como foi bem observado por Oliveira (2003), o 
Censo Demográfico reflete a agenda de preocupações de seu tempo, da sociedade e do governo do momento de sua realização, além de projetar o sonho de cada nação no futuro imediato, ao explicitar novas demandas de políticas. A extensão do questionário e, sobretudo, o conjunto de quesitos investigados refletem a "cara" da sociedade à época de seu levantamento. Assim, o primeiro Censo brasileiro, realizado em 1872, levantou apenas 14 quesitos de informação, entre características demográficas, religião, profissão e condição civil (livre ou escravo). Em 2010, o Censo dispôs de mais de 90 quesitos no questionário, ampliando consideravelmente a caracterização socioeconômica da população, dos domicílios e entorno da moradia.

Os Censos certamente fortaleceram a capacidade de agendamento de prioridades na pauta de políticas públicas nesses quase 150 anos. Para citar um campo específico de políticas - trabalho e formação -, foi fundamental dispor nas últimas décadas de dados municipais sobre existência de trabalho infantil - e do tipo de ocupação exercida pelas crianças -, estrutura ocupacional (para fins de identificação de base sindical e necessidades de qualificação profissional), perfil setorial das atividades econômicas (para projetos de desenvolvimento local e regional) e caracterização das relações de trabalho (para dimensionamento da informalidade em nível local).

Além da abrangência temática, a cobertura nacional e a ampla capacidade de desagregação geográfica e por grupo sociodemográfico tornam o Censo uma fonte de grande utilidade para o planejamento público, nas três esferas de governo. Por definição, os recenseamentos cobrem a totalidade do território e fornecem dados desagregados em nível de grandes regiões, unidades da federação, meso e microrregiões, municípios, distritos e, até mesmo, em âmbito de setor censitário ou área de ponderação. Esse plano multinível de disponibilização de dados censitários permite a formulação de programas públicos com graus de detalhamento e alcance bastante variados, adequados ao tamanho, aos volumes de recursos, à abrangência geográfica e aos objetivos políticos das diferentes esferas de governo. Por intermédio dos dados censitários, podem-se estimar demandas sociais universais a serem atendidas nas áreas da saúde, educação e emprego, assim como o tamanho do público-alvo específico de alguns programas sociais focalizados. Além disso, os dados censitários possibilitam delimitar, com uma razoável precisão geográfica, em uma escala inframunicipal, as áreas não atendidas por serviços públicos, os bolsões de pobreza, os pontos ou manchas urbanas que requerem programas de ação pública. Também é possível computar indicadores sociais para segmentos populacionais específicos por raça/cor ou ciclo geracional (crianças, jovens, adultos, idosos e até mesmo os centenários).

Essa granularidade territorial do Censo Demográfico pode explicar, em alguma medida, a reconhecida focalização do programa Bolsa Família junto à população mais pobre (CAMPELLO; FALCÃO, 2014). Aplicativos de consulta às estatísticas de pobreza e vulnerabilidade social, com desagregação em nível de setor censitário e áreas de ponderação, foram disponibilizados para que equipes municipais do Cadastro Único de Programas Sociais e 
da Assistência Social pudessem chegar aos públicos-alvo das políticas de desenvolvimento social, no campo e nas periferias das maiores cidades (JANNUZZI et al., 2014).

O Censo brasileiro é, em termos internacionais, um dos mais detalhados. Não se trata de um capricho "jaboticabino", mas sim uma decorrência das lacunas e deficiências dos sistemas municipais de informação e cadastros públicos. Os Censos constituem fonte quase que exclusiva de informação para planejamento e formulação de políticas em âmbitos local e microlocal, uma vez que os cadastros e registros administrativos públicos na esfera municipal apresentam problemas de atualização e confiabilidade, não têm cobertura espacial ou populacional muito abrangente ou ainda não dispõem de referenciamento geográfico. Em alguns países mais ricos, de população de algumas dezenas de milhões, em que a cobertura dos registros de nascimentos, casamentos, mobilidade residencial e óbitos é universal, os levantamentos censitários vêm sendo abandonados. Esse não é certamente o caso do Brasil de 2020.

Para além dessas finalidades, os Censos permanecem como fonte fundamental para contabilizar o tamanho da população brasileira e seu perfil em termos de sexo, idade, raça/cor e religião. Não menos importante é o fato de que os levantamentos censitários cumprem uma função normativa importante no sistema político - na definição de vagas de representação legislativa - e no sistema tributário - na repartição dos recursos arrecadados em impostos pelo setor público (HAKKERT, 1996).

\section{A contribuição das Munic e PNAD na gestão de políticas públicas}

Em um país com as dimensões continentais e estrutura federativa como o Brasil, políticas e programas devem ser desenhados para atender às demandas sociais, mas precisam estar adequados à estrutura de gestão existente. Propostas meritórias de programas, com desenhos lógicos consistentes “em tese”, podem ser inviabilizadas pelos problemas de implementação decorrentes de baixa capacidade de gestão de agentes encarregados da operação em um dos "nós críticos" do programa, em municípios, estados ou departamentos de um determinado Ministério. Enfim, além de um bom diagnóstico socioeconômico, o sucesso de uma política ou programa depende da disponibilidade de informações acerca da capacidade de gestão e implementação dos agentes públicos envolvidos, nos diferentes contextos de atuação. Indicadores de estrutura de gestão e de oferta de serviços referem-se, principalmente, à caracterização dos recursos humanos - dimensionamento, formação, valores, etc. -, dos equipamentos sociais usados - adequação física, acessibilidade, cobertura territorial, etc. - e dos recursos orçamentários - suficiência, regularidade de desembolso, etc.

Essas são as principais contribuições das edições anuais da Munic desde 1999 (e da Estadic desde 2012). Esses levantamentos, realizados em todas as prefeituras (e estados) do país, permitem construir indicadores para retratar o grau de participação e controle popular da ação pública e também indicadores para caracterizar o estágio de desenvolvimento institucional para as atividades de planejamento e capacidade de gestão pelo país. 
A pesquisa tem sido usada pelos Ministérios para levantar, em suplementos específicos anuais, aspectos da gestão municipal necessários à implementação de programas e políticas federais, como no caso da cultura, esportes, assistência social, segurança alimentar, inclusão produtiva, direitos humanos, entre outros. A implementação da política de assistência social e a agenda ambiental em nível subnacional têm sido acompanhadas por meio dessas pesquisas, para citar dois exemplos. Vale mencionar também que a estratégia de formação técnica de agentes locais de inclusão produtiva formulada em 2014 - para implementação a partir de 2015 - valeu-se fortemente do levantamento da Munic 2014, sobre as iniciativas municipais e estaduais nesse campo setorial de política, como revela o material desenvolvido pelo Cegov (2016).

0 monitoramento e a avaliação de políticas e programas sociais - outra atividade crucial para efetividade dos mesmos - têm sido viabilizados sobretudo com a PNAD, seus suplementos temáticos específicos e, mais recentemente, com a PNAD-C. Se essas pesquisas têm limitações no acompanhamento de programas específicos, é fato que permitem avaliações bastante robustas de efeitos integrados de conjuntos de políticas sociais, em diferentes contextos regionais, públicos e escalas geográficas. Desde que foi criada em 1967 com objetivo de captar informações para acompanhamento da conjuntura do mercado de trabalho, a PNAD vem expandindo seu escopo investigativo e sua representatividade no território nacional (IBGE, 2015). Várias temáticas de interesse da agenda das políticas públicas no país foram investigadas ao longo das edições anuais da pesquisa, tais como trabalho infantil, situação do menor, ensino supletivo, acesso a serviços de saúde, acesso a programas sociais, vitimização, segurança alimentar e, mais recentemente, acesso às tecnologias da informação e comunicação, inclusão produtiva e cuidados da primeira infância. Sua amostra foi aumentando de modo a cobrir a totalidade do território brasileiro e permitir a computação de estatísticas e indicadores sociais com razoável precisão.

As informações disponíveis anualmente sobre inserção ocupacional, perfil educacional, condições de moradia e características demográficas subsidiaram um volume incontável de estudos acadêmicos (OLIVEIRA; SIMÕES, 2005). Os indicadores sociais produzidos com a pesquisa têm sido fundamentais para atualizar os retratos dos Censos Demográficos na proposição de novas políticas e programas públicos nos Ministérios. A PNAD tem sido imprescindivel nas avaliações anuais do Plano Plurianual dos governos federal e estaduais (BRASIL, 2010) e na produção de relatórios de acompanhamento das agendas de compromissos internacionais ou de desenvolvimento, como os Relatórios de Acompanhamento dos Objetivos do Milênio (IPEA, 2014).

Para citar usos instrumentais mais recentes em políticas públicas, vale destacar o papel da pesquisa na legitimação, formulação e gestão das políticas de desenvolvimento social. A PNAD teve papel fundamental para garantir a legitimidade da agenda de combate à fome nos anos 2000, por meio das ações do Fome Zero, Bolsa Família e Plano Brasil Sem Miséria (BRASIL, 2016). 0 suplemento sobre insegurança alimentar de 2004 mostrou que, embora a desnutrição infantil estivesse em patamares bastante baixos - como revelado pela 
Pesquisa de Orçamento Familiar de 2002/03 -, a situação potencial e efetiva de restrição alimentar acometia quase um quinto das famílias brasileiras. Os suplementos de acesso a programas sociais em 2004, 2006 e 2014 permitiram avaliar a cobertura do programa Bolsa Família, mostrar sua adequada focalização e desmistificar falsas assertivas acerca do nível da fecundidade e da participação econômica das famílias mais pobres, como revela a coletânea organizada por Neri e Campello (2013). Os indicadores de pobreza monetária computados pelas edições anuais da pesquisa também foram fundamentais no monitoramento - e legitimação - do Bolsa Família, como argumentado por Rocha (2012), e permitiram constatar a efetividade da estratégia de combate à fome e pobreza extrema no período.

\section{Considerações finais}

Pelas características de seu sistema estatístico e natureza estruturante de seu sistema de proteção social, o Brasil é, sem dúvida, um caso em que a produção ampliada e regular de indicadores sociais tem cumprido papel fundamental para formulação e legitimação de políticas públicas. Se não houvesse Censos Demográficos, realizados de forma regular há 80 anos, se não tivessem sido criadas, há 50 anos, a Pesquisa Nacional por Amostra de Domicílios (PNAD) e, há quase 20 anos, a Pesquisa de Informações Básicas Municipais (Munic), os avanços sociais observados no país certamente seriam menores. As políticas públicas não teriam a cobertura e impacto social que muito estudos têm demonstrado. Sem esta regularidade e abrangência temática das pesquisas nem mesmo poder-se-ia dimensionar tais avanços e iniquidades persistentes. Não teriam sido produzidos evidências concretas para estudos e pesquisas nas Ciências Sociais no país e relatórios sociais diversos, como a Síntese de Indicadores Sociais, iniciada em 1979 pelo IBGE (SIMÕES; ALKMIM; SANTOS, 2017).

Nesse sentido, dado esse "histórico de serviços", são preocupantes os rumores de que o questionário do Censo 2020 teria que ser significativamente reduzido para se adequar às contingências orçamentárias do presente. Se é necessário garantir maior eficácia, efetividade e eficiência dos recursos públicos, não parece que excluir quesitos de informação tão relevantes pode ajudar no médio e longo prazos nesses objetivos. A economia de recursos no curto prazo vai significar dez anos de estimação mais imprecisa de públicos-alvo de políticas, implicando sobre ou subdimensionamento de investimentos públicos e privados em equipamentos de saúde, creches, transporte urbano, para citar alguns dos setores mais afetados pela perda de capacidade de planejamento e avaliação. Eficiência e efetividade seriam certamente comprometidas, justamente no momento em que as políticas públicas começam a superar problemas básicos de implementação. Vale lembrar um episódio recente bastante semelhante: a retirada de quesitos que investigavam mais profundamente o uso de agrotóxicos no Censo Agropecuário de 2017 limita bastante a possibilidade de regulação estatal e desenho de intervenções públicas em saúde para mitigar as consequências abusivas desses produtos. 
Seria possível argumentar que os cortes no orçamento federal para o Censo poderiam, em tese, ser compensados pela disponibilidade de informações administrativas das políticas públicas. Os avanços na estruturação e na qualidade da informação dos cadastros e registros públicos têm contribuído bastante nesse sentido, como demonstra o uso do Cadastro Único de Programas Sociais para dimensionamento de demandas sociais da população mais pobre e sua identificação no território, dos levantamentos censitários do Inep para caracterização da infraestrutura escolar ou mensuração do desempenho discente e dos registros dos programas do Sistema Único da Saúde e do Ministério do Trabalho. Mas esses dados referem-se a acesso ou prestação de serviços e não propriamente à demanda social captada nos domicílios no vasto território brasileiro, onde alguns dos serviços públicos apresentam problemas de cobertura e regularidade de oferta.

Poder-se-ia supor que haveria aportes adicionais nos orçamentos estaduais e municipais nos próximos anos para levantar o que não se coletou no Censo. Investimento na produção de informação diagnóstica complementar é certamente bem-vindo, mas estariam os estados e municípios com capacidade técnica e operacional para realizar seus próprios Censos, com informação abrangente, precisa e detalhada territorialmente? Teriam os recursos orçamentários para isso, especialmente os municípios ou estados mais pobres, onde a informação estatística seria ainda mais imprescindível?

Poder-se-ia imaginar que o "Big Data" - as informações públicas e privadas que trafegam na Internet - pode complementar o acervo de dados requerido para o planejamento e monitoramento da ação governamental. Sem negar o uso que esses dados podem vir a ter no futuro, há muito que se avançar na estruturação de algoritmos confiáveis para produção regular, comparável no tempo e território e, sobretudo, na captação de informação, de fato, relevante e abrangente sobre temas “invisíveis” às redes, como o são muitas das problemáticas sociais no país.

Informação de boa qualidade, para propósitos tão abrangentes como os demandados para as políticas públicas no Brasil, tem um custo elevado de produção. Afinal, nos Censos Demográficos, são mais de 300 mil pessoas mobilizadas, percorrendo as ruas, vielas e zona rural em todos os mais de 5,5 mil municípios do país. 0 pessoal recrutado precisa passar por um treinamento detalhado, para que a realização do trabalho de campo transcorra normalmente durante os três ou quatro meses previstos de coleta de dados. É uma experiência muito diferente de países menores, menos populosos ou de nível educacional elevado, onde as entrevistas podem ser realizadas pelos professores da rede pública ou os questionários preenchidos pelos respondentes pela Internet.

É fato que o papel e a importância das pesquisas do IBGE, em especial dos Censos Demográficos, PNAD e Munic, no processo de formulação e avaliação de políticas públicas, são ainda um tema pouco estudado, ou pelo menos pouco reverberado, como são, em geral, os esforços meritórios de gestão e inovação no setor público. A re-edição de Indicadores sociais no Brasil, mais de 15 anos depois, com um capítulo sobre indicadores e políticas sociais, foi um esforço nesse sentido (JANNUZZI, 2017). Registros institucionais, como os organizados por Senra et al. (2015), mostram como a agenda de políticas públicas tem se rebatido sobre 
- IBGE em busca de respostas para as demandas de Estado e governo, mas ainda é raro o reconhecimento da importância das estatísticas para o sucesso dessas políticas.

Certamente a efetividade das políticas públicas depende de muitos outros fatores institucionais e operacionais, mas a disponibilidade da informação estatística de boa qualidade e regularidade potencializa as chances de sucesso, ao permitir a identificação de demandas sociais latentes na sociedade (e sua vocalização por grupos interessados em influenciar a agenda governamental), viabilizar a elaboração de diagnósticos mais robustos em escopo e escala territorial, possibilitar o mapeamento de capacidade de gestão e atendimento de serviços no território e oportunizar indicadores de monitoramento e avaliação, mais gerais e às vezes mais específicos, de políticas e programas.

Nenhum Estado, por menor que seja sua ambição civilizatória, pode prescindir das estatísticas, das informações sobre o "estado do Estado". Estatísticas públicas ajudam pautar agendas políticas, qualificar debates públicos e subsidiar decisões técnico-políticas. Prestam-se para dimensionar a população e suas demandas, avaliar o nível médio de bem-estar, investigar as iniquidades sociais existentes e avaliar os efeitos da ação ou inação de suas políticas. Como mostrou a experiência histórica dos países desenvolvidos, o volume de recursos, a abrangência de temas investigados e a cobertura e regularidade das pesquisas refletem o escopo e escala que a sociedade confere às políticas públicas. Concepções mais amplas - ou mais estreitas - de Estado de Bem-Estar demandam sistemas mais complexos - ou mais modestos - de informação estatística.

0 pacto progressista e civilizatório vocalizado pela Constituição Federal de 1988 e os desafios do desenvolvimento no presente século, como bem apontam Stiglitz et al. (2014), requerem a continuidade do esforço de estruturação do Sistema Estatístico. Mais recursos, pesquisas mais amplas, mais informação, maior eficiência, eficácia e efetividade das políticas públicas!

\section{Referências}

BRASIL. Ministério do Desenvolvimento Social e Combate à Fome. SAGI: informação e conhecimento para as políticas de desenvolvimento social. Brasília: Secretaria de Avaliação e Gestão da Informação, 2016.

BRASIL. Ministério do Planejamento, Orçamento e Gestão. Indicadores de programas. Guia de elaboração. Brasília, 2010.

CAMPELLO, T.; FALCÃO, T. Fim da miséria é só o começo. In: CAMPELLO, T.; FALCÃO, T.; COSTA, P. V. (Org.). O Brasil Sem Miséria. Brasília: Ministério do Desenvolvimento Social, 2014. p.793-822.

CEGOV - Centro de Estudos Internacionais sobre Governo. Caderno de estudos do curso em mapeamento de oportunidades e iniciativas de inclusão produtiva. Brasília: Ministério do Desenvolvimento Social e Combate à Fome/Secretaria de Avaliação e Gestão da Informação (MDS/Sagi), 2016.

IBGE - Instituto Brasileiro de Geografia e Estatística. PNAD: um registro histórico 1967-2015. Rio de Janeiro, 2015. 
IPEA - Instituto de Pesquisa Econômica Aplicada. Objetivos de Desenvolvimento do Milênio: 5ํ Relatório Nacional de Acompanhamento. Brasília, 2014.

JANNUZZI, P. M. Monitoramento e avaliação de programas sociais: uma introdução aos conceitos e técnicas. Campinas: Alínea, 2016.

Indicadores sociais no Brasil: conceitos, fontes de dados e aplicações. 6. ed. rev. e ampl. Campinas: Alínea, 2017.

JANNUZZI, P. M. et al. Construindo mapas de pobreza, serviços públicos e de oportunidades para o Plano Brasil Sem Miséria. Cadernos de Estudos Desenvolvimento Social em Debate, Brasília, n. 19, p. 78-87, 2014.

HAKKERT, R. Fontes de dados demográficos. Belo Horizonte: Abep, 1996.

HOWLETT, M.; RAMESH, M.; PERL, A. Política pública, seus ciclos e subsistemas. Rio de Janeiro: Ed. Campus, 2013.

NERI, M.; CAMPELLO, T. Programa Bolsa Família: uma década de inclusão e cidadania. Brasília: Ipea, 2013.

OLIVEIRA, L. A. P.; SIMÕES, C. C. S. O IBGE e as pesquisas populacionais. Revista Brasileira de Estudos da População, São Paulo, v. 22, n. 2, p. 291-302, jul./dez. 2005.

OLIVEIRA, J. S. "Brasil mostra a tua cara": imagens da população brasileira nos censos demográficos de 1872 a 2000. Rio de Janeiro: Escola Nacional de Ciências Estatísticas, 2003 (Textos para discussão).

ROCHA, S. Transferências de renda no Brasil: o fim da pobreza? Rio de Janeiro: Elsevier, 2013.

SENRA, N. et al. 0 desafio de retratar o país: entrevistas com os presidentes do IBGE no período de 1985 a 2015. Rio de Janeiro: IBGE, 2015.

SIMÕES, A.; ALKMIM, A. C.; SANTOS, C. Passado, presente e futuro da produção e análise dos Indicadores Sociais no IBGE. In: SIMÕES, A.; ALKMIM, A. C. Indicadores sociais: passado, presente e futuro. Rio de Janeiro: IBGE, 2017. p.17-27.

STIGLITZ, J. E.; SEN, A.; FITOUSSI, J. P. Mis-mesuring our lives: why GDP doesn`t add up. New York: New Press, 2014.

\section{Sobre 0 autor}

Paulo de Martino Jannuzzi é mestre em Administração Pública pela Escola de Administração de Empresas de São Paulo (EAESP/FGV) e doutor em Demografia pela Universidade Estadual de Campinas (Unicamp). Professor na Escola Nacional de Ciências Estatísticas (Ence) do Instituto Brasileiro de Geografia e Estatística (IBGE) e na Faculdade Cesgranrio. Pesquisador CNPq no projeto “Políticas Públicas, Mudança Social e Dinâmica Demográfica no Brasil de 1992 a 2014 ”.

\section{Endereço para correspondência}

\section{Ence/IBGE}

Rua André Cavalcanti 106, sala 501-B

20231-050 - Rio de Janeiro-RJ, Brasil 